\title{
Secretion of Streptomyces tendae antifungal protein 1 by Lactococcus lactis
}

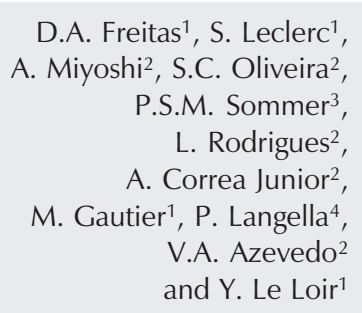

D.A. Freitas ${ }^{1}$, S. Leclerc ${ }^{1}$, A. Miyoshi², S.C. Oliveira ${ }^{2}$, P.S.M. Sommer ${ }^{3}$,

L. Rodrigues ${ }^{2}$, A. Correa Junior ${ }^{2}$, M. Gautier ${ }^{1}$, P. Langella ${ }^{4}$, V.A. Azevedo ${ }^{2}$ and Y. Le Loir ${ }^{1}$

\author{
${ }^{1}$ Laboratory of Microbiology, UMR1253 STLO, Agrocampus INRA \\ (National Institute for Agricultural Research), Rennes Cedex, France \\ 2Instituto de Ciências Biológicas, Universidade Federal de Minas Gerais, \\ Belo Horizonte, MG, Brasil \\ ${ }^{3}$ Departamento de Biologia Celular e Genética, Centro de Biociências, \\ Universidade Federal do Rio Grande do Norte, Natal, RN, Brasil \\ ${ }^{4}$ Laboratory of Applied Genetics, Unit of Dairy Research and Applied Genetics, \\ National Institute for Agricultural Research, Domaine de Vilvert, Jouy en Josas Cedex, \\ France
}

\section{Correspondence \\ Y. Le Loir \\ Laboratoire de Microbiologie UMR1253 STLO, INRA - Agrocampus 65, rue de Saint Brieuc CS84215 35042 Rennes Cedex \\ France \\ Fax: +33-2-2348-5902 \\ E-mail: Yves.LeLoir@rennes.inra.fr \\ D. Freitas, A. Miyoshi, and S. Leclercq were recipients of CAPES fellowships (project CAPES-COFECUB \#319-II). \\ V. Azevedo and Y. Le Loir share the credit for senior authorship.}

Received November 19, 2004

Accepted July 27, 2005

\begin{abstract}
Lactococcus lactis, the model lactic acid bacterium, is a good candidate for heterologous protein production in both foodstuffs and the digestive tract. We attempted to produce Streptomyces tendae antifungal protein 1 (Afp1) in L. lactis with the objective of constructing a strain able to limit fungal growth. Since Afp1 activity requires disulfide bond (DSB) formation and since intracellular redox conditions are reportedly unfavorable for DSB formation in prokaryotes, Afp1 was produced as a secreted form. An inducible expression-secretion system was used to drive Afp1 secretion by L. lactis; Afp1 was fused or not with LEISSTCDA, a synthetic propeptide (LEISS) that has been described to be a secretion enhancer. Production of Afp1 alone was not achieved, but production of LEISS-Afp1 was confirmed by Western blot and immunodetection with anti-Afp1 antibodies. This protein (molecular mass: $9.8 \mathrm{kDa}$ ) is the smallest non-bacteriocin heterologous protein ever reported to be secreted in L. lactis via the Sec-dependent pathway. However, no anti-fungal activity was detected, even in concentrated samples of induced supernatant. This could be due to a too low secretion yield of Afp1 in L. lactis, to the absence of DSB formation, or to an improper DSB formation involving the additional cysteine residue included in LEISS propeptide. This raises questions about size limits, conformation problems, and protein secretion yields in L. lactis.
\end{abstract}

Key words

- Lactococcus lactis

- Antifungal protein

- Secretion

- Streptomyces tendae antifungal protein 1

\section{Introduction}

Lactic acid bacteria (LAB) are anaerobic Gram-positive bacteria capable of fermenting sugars, primarily to lactic acid. They are widely used in agriculture and in the food industry to produce fermented food from plant and animal products, and more recently they have been considered to be good candidates for heterologous protein production. Since 1990, new uses for LAB have been intensively explored, such as the pro- 
duction of proteins of therapeutic interest (1). The ability of Lactococcus lactis, the model LAB, to produce and export heterologous proteins has been widely exploited. Many proteins have already been produced through a Sec-dependent pathway (2). Gene expression in L. lactis has been improved in a number of ways in order to achieve efficient heterologous protein production. These include development of strong and inducible promoters and high-copy number vectors, and improved codon usage. However, even with such refined production systems, secretion of the heterologous protein into the culture supernatant can still be a limiting step in obtaining high yields of exported proteins. Consequently, an understanding of the molecular processes involved in protein secretion has become important for both basic and applied research. Secretion of highmolecular weight proteins such as dextran sucrase (165 kDa) has been reported for $L$. lactis (3); however, little is known about the ability of L. lactis to secrete low-molecular weight proteins, even though this feature has been found to be a limiting step for protein production in other bacteria (4).

Antifungal protein 1 (Afp1) is an 86residue protein naturally secreted by Streptomyces tendae Tü901. Afp1 is the first chitinbinding protein known to have antifungal activity. It is very stable under a wide range of $\mathrm{pH}$ and temperature conditions and is highly resistant to proteolysis (5). At rather high concentrations, Afp1 by itself is able to inhibit the growth of several fungal species.

Thus, Afp1 was considered to be a good candidate for the construction of recombinant $L$. lactis strains harboring anti-fungal activity. Afp1 is also a good candidate to test the ability of L. lactis to secrete and properly fold heterologous proteins. Afp1 contains one disulfide bond (DSB), which is required for anti-fungal activity and which may be involved in its high stability (5). Even though several proteins containing DSBs have been successfully secreted in L. lactis, the rates of production of such proteins have been low (6-9).

An Afp1-producing L. lactis strain could be used to avoid undesirable fungal contamination in fermented food products. Some fungi are spoiling agents or can produce health-threatening mycotoxins (10). For many years, LAB strain libraries have been screened for antimicrobial activity towards bacterial pathogens, instead of for their antimicrobial activities against yeasts and fungi. Recently, several LAB have been screened for antifungal activity, an attribute that has often been described as a multifactorial trait involving organic acid $(11,12)$ and cyclic dipeptide production (13). However, antifungal activity is often an unstable trait in LAB (14). Moreover, protein antifungal compounds isolated from LAB, such as Lactobacillus coryniformis, are reportedly sensitive to proteolysis and to temperature changes, and are only active within a narrow pH range (15). An Afp1-producing L. lactis strain would constitute a new antifungal LAB, secreting a well-characterized and highly stable antifungal toxin.

We were able to construct an L. lactissecreting Afp1 through a Sec-dependent pathway. To our knowledge, Afp1 is the shortest non-bacteriocin protein ever secreted in L. lactis. This shows that L. lactis is able to secrete non-bacteriocin proteins as short as $9.8 \mathrm{kDa}$. However, samples of culture supernatant of the Afp1-producing strains did not harbor any antifungal activity.

\section{Material and Methods}

\section{Bacterial strains, plasmids, media, and growth conditions}

E. coli strain TG1 (16), and L. lactis NZ9000 (17) were used as hosts. The plasmids used are described in Table 1. E. coli was grown on Luria-Bertani medium (LB, Difco, Becton Dickinson, Le Pont-De-Claix, France) and incubated at $37^{\circ} \mathrm{C}$. L. lactis was 
grown on M17 medium, in which lactose was replaced with $0.5 \%$ glucose (M17-glu; Difco), and incubated at $30^{\circ} \mathrm{C}$. Antibiotics were added at the following concentrations: $5 \mu \mathrm{g} / \mathrm{mL}$ chloramphenicol for L. lactis and E. coli and $100 \mu \mathrm{g} / \mathrm{mL}$ ampicillin for $E$. coli. Induction of the nisin promoter was carried out as follows: an overnight culture was diluted 1:250 into fresh medium and incubated at $30^{\circ} \mathrm{C}$ until the absorbance at $600 \mathrm{~nm}$ reached $\sim 0.5$. The culture was then divided into two equal volumes, and $1 \mathrm{ng} / \mathrm{mL}$ (or 10 $\mathrm{ng} / \mathrm{mL}$ to increase the induction level) of nisin was added to one tube. The other tube was kept as the non-induced culture control. Cultures were incubated and protein samples were prepared for Western blot analysis or for activity test after $1 \mathrm{~h}$ of induction.

\section{DNA manipulation}

Plasmid DNA was isolated essentially as described (18), except for L. lactis, in which TES buffer (25\% sucrose, 1 mM EDTA, 50 $\mathrm{mM}$ Tris- $\mathrm{HCl}, \mathrm{pH} 8$ ) containing $10 \mathrm{mg} / \mathrm{mL}$ of lysozyme was used for $10 \mathrm{~min}$ at $37^{\circ} \mathrm{C}$ to prepare the protoplasts. Enzymes were used as recommended by the suppliers. General procedures for DNA manipulation were performed as described (19). Electroporation of L. lactis was performed as described (20), and transformants were plated onto M17-glu agar plates containing the required antibiotics.

PCR assays were performed on a PerkinElmer/Cetus (Norwalk, CT, USA) apparatus using Thermophilus aquaticus DNA polymerase (Promega Corp., Madison, WI, USA), as recommended by the manufacturer. Oligonucleotides were synthesized by Sigma Genosis (Haverhill, UK). All constructions were confirmed by DNA sequencing using the ABI Prism BigDye Terminator Cycle Sequencing Ready Reaction Kit (PE-Applied Biosystems, Courtaboeuf, France) as recommended by the manufacturer. Constructions were obtained in E. coli TG1 and then established in L. lactis NZ9000 (kindly provided by O. Kuipers; Ref. 21), a derivative of L. lactis MG1363 that carries the $n i s R K$ regulatory genes.

\section{Plasmid constructions}

To construct pSEC-Afp1 and pSECLEISS-Afp1 (Table 1), an afp1 DNA fragment corresponding to the mature moiety of the Afp 1 protein was amplified by PCR from the previously described plasmid pUCK11 (5). The oligonucleotides used were 5'GGATGCATCCGGCCCGACCATCAAC3 ' for the coding strand and 5'-GGGAATTC CCGGCGCTTTCGAGTAAG-3' for the complementary strand. Restriction sites Nsi I and $E c o$ RI (underlined) were introduced at 5 ' and 3', respectively, for subsequent cloning in pSEC and pSEC-LEISS vectors (22). The afp1 PCR-amplified fragment ( 270 bp) was first ligated to pGEM-T (Promega), resulting in a plasmid called pGEM-T:afpl (Table 1), obtained by transformation of the E. coli TG1 strain (16). The afpl fragment

Table 1. Plasmids used in the present study.

\begin{tabular}{|c|c|c|c|}
\hline Plasmids & Replicon & Plasmid characteristics & Reference \\
\hline pGEM-T & & Ampr. Cloning vector for PCR products & $\begin{array}{c}\text { Promega, } \\
\text { Madison, WI, USA }\end{array}$ \\
\hline pGEM-T:afp1 & & Ampr. PCR fragment encoding the mature moiety of Afp1 & Present study \\
\hline pSEC-E7 & pWV01 & $\mathrm{Cm}^{\mathrm{r}}$; gene, expressed under $\mathrm{P}_{\text {nisA }}$ encodes $\mathrm{SP}$ Usp-E7 precursor & 22 \\
\hline pSEC-LEISS-E7 & pWV01 & $\mathrm{Cm}^{\mathrm{r}}$; gene, expressed under $\mathrm{P}_{\text {nisA }}$ encodes SPUsp-LEISSTCDA-E7 precursor & 22 \\
\hline pSEC-LEISS-Nuc & pWV01 & $\mathrm{Cm}^{\mathrm{r}}$; gene, expressed under $\mathrm{P}_{\text {nis }}$ encodes $\mathrm{SP}_{\text {Usp-LEISSTCDA-Nuc precursor }}$ & 24 \\
\hline pSEC-Afp1 & pWV01 & $\mathrm{Cm}^{\mathrm{r}}$; gene, expressed under $\mathrm{P}_{\text {nisA }}$ encodes SPUsp-Afp1 precursor & Present study \\
\hline pSEC-LEISS-Afp1 & pWV01 & $\mathrm{Cm}^{\mathrm{r}}$; gene, expressed under $\mathrm{P}_{\text {nisA }}$ encodes SPUsp-LEISSTCDA-E7 precursor & Present study \\
\hline
\end{tabular}


was purified from an NsiI/EcoRI-digested pGEM-T:afpl and inserted into pSEC and pSEC-LEISS backbones digested with the same enzymes and purified from pSEC-E7 and pSEC-LEISS-E7, as previously described (Table 1, Ref. 22).

\section{Preparation of protein extracts and detection} of Afp1 by immunoblotting

Since Afp1 is a small protein, the preparation of samples from $L$. lactis cultures was modified from the previous protocol based on trichloroacetic acid precipitation (22). Briefly, for cell fractionation, $2 \mathrm{~mL}$ L. lactis exponential phase cultures was harvested after 5 min centrifugation at $6,000 \mathrm{~g}$ at $4^{\circ} \mathrm{C}$. Cell and supernatant fractions were treated separately and supernatants were filtered through $0.2-\mu \mathrm{m}$ pore filters (Millipore, Bedford, MA, USA). Samples of culture supernatant from induced and non-induced cultures were $\sim 10$-fold concentrated by filtration through nitrocellulose membranes with a cut-off of $5 \mathrm{kDa}$ (Ultrafree-MC 5,000 NMWL Filter Unit, Amicon, Millipore). Cell pellets were washed and resuspended in TES prior to trichloroacetic acid precipitation (10\% final concentration). Cell pellets were then washed once with $1 \mathrm{~mL}$ of cold acetone, dried, and resuspended in TES containing lysozyme $\left(1 \mathrm{mg} / \mathrm{mL} ; 30 \mathrm{~min}\right.$ at $\left.37^{\circ} \mathrm{C}\right)$. Cells were lysed with $20 \%$ SDS and the cell fraction was also concentrated $\sim 10$-fold. An equal volume of $2 \mathrm{X}$ loading buffer was added to all samples. Both supernatant and cell fractions were denatured for $5 \mathrm{~min}$ at $95^{\circ} \mathrm{C}$ prior to SDS-PAGE.

The Afp1 protein purified from Streptomyces tendae supernatant (kindly provided by C. Bormann, University of Tübingen, Tübingen, Germany) was used as a positive control. SDS-PAGE was performed on $15 \%$ acrylamide gels to obtain good resolution for the low-molecular weight proteins. Proteins separated by SDS-PAGE were transferred onto PVDF membranes (Millipore) and immunoblotting was performed as previously described (19), or according to manufacturer recommendations. Rabbit anti-Afp1 antibodies were kindly provided by $\mathrm{C}$. Bormann. Immunodetection was performed using the protein $G$ horseradish peroxidase conjugate (BioRad, Marnes la Coquette, France) and the ECL kit (Dupont-NEN, Boston, MA, USA), as recommended by the manufacturers.

\section{Antifungal activity}

The effect of the Afp1 secreted by $L$. lactis on fungal growth was assessed by an in vitro assay, using the fungi Paecilomyces variotti (ATCC-22319), Aspergillus fumigatus (ATCC-16913) and Trichophyton mentagrophytes (ATCC-11481) as indicators. $P$. variotti and A. fumigatus were grown on Czapek Dox medium, while T. mentagrophytes was grown on Sabouraud solid medium. Fungal spores were harvested from 7 day cultures to obtain a $10^{4}$ cells $/ \mathrm{mL}$ suspension in sterile water. One milliliter of this solution was spread onto a 9-cm diameter Petri dish containing the appropriate solid culture media. The supernatant (1 liter) of an induced NZ(pSEC-LEISS-Afp1) culture was freeze-dried and resuspended in water (10 $\mathrm{mL}$ ). This 100 -fold concentrated solution was diluted to $1 / 10,1 / 100$ and $1 / 1000$. One hundred-microliter aliquots of these dilutions were deposited onto 6-mm sterile Whatman \#1 paper discs (Whatmann International Ltd., Maidstone, UK) and vacuum dried. Equal amounts of water, NZ(pSECLEISS-Afp1) supernatant (not freeze-dried) and culture medium were also deposited onto paper discs and used as negative controls. Afp1 (provided by C. Bormann) was used as a positive control. The discs were laid on the top of the fungal culture and incubated for 3 days. The $P$. variotti plates were maintained at $37^{\circ} \mathrm{C}$, while A. fumigatus and T. mentagrophytes were kept at $25^{\circ} \mathrm{C}$. The experiments were performed in triplicate. 


\section{Results and Discussion}

\section{Construction of the Afp1-producing \\ Lactococcus lactis strains}

Since Afp1 requires a single DSB for antifungal activity, and since intracytoplasmic redox conditions are unfavorable for DSB formation (23), the previously described lactococcal pSEC and pSEC-LEISS plasmids (8) were used for Afp1 secretion in $L$. lactis. The pSEC-LEISS backbone allows for fusion between the protein of interest and the LEISSTCDA propeptide (hereafter referred to as LEISS), which was demonstrated to be an enhancer of secretion of several heterologous proteins by L. lactis (19). The resulting plasmids, termed pSEC-Afp1 and pSEC-LEISS-Afp1, were constructed as described in Material and Methods, obtained in $E$. coli TG1, and then introduced into $L$. lactis NZ9000, resulting in the strains NZ(pSEC-Afp1) and NZ(pSEC-LEISSAfp1) (Figure 1). These strains were used for the analysis of Afp1 secretion in L. lactis.

\section{Lactococcus lactis secretes LEISS-Afp1, but not Afp1}

Afp1 production and secretion was analyzed in L. lactis NZ(pSEC-Afp1) and NZ(pSEC-LEISS-Afp1) by Western blot and by immunodetection with anti-Afp1 antibodies. Recombinant strains were grown to absorbance at $600 \mathrm{~nm}=0.4-0.6$ and then induced for $1 \mathrm{~h}$ as described in Material and Methods. Protein samples were prepared from induced cultures of NZ(pSEC-Afp1) and NZ(pSEC-LEISS-Afp1). An L. lactis strain NZ(pSEC-LEISS-Nuc) that secretes Staphylococcus aureus nuclease (24) was used as a negative control. Afp1 was not detected in induced supernatants of NZ (pSEC-Afp1) in our Western blot analysis. Cell fraction analysis revealed a band that co-migrates with Afp1. This band was present in the induced and non-induced cell frac- tions of the negative control, NZ(pSECLEISS-Nuc). The intensity of this band was not correlated with the nisin induction levels used for protein production in the pSEC vectors, whereas the intensity was proportional to the induction level when the signal corresponded to an induced protein, as previously demonstrated $(24,25)$. Thus, this band was probably due to cross-reactions of the anti-Afp1 antiserum with lactococcal intracellular, or surface, proteins (Figure 2A). We then focused our analysis on the supernatant fractions since, based on the redox conditions, the secreted form is the only form of Afp1 that would have a proper conformation as a result of correct DSB formation. Afp1 was detectable in supernatant samples of the NZ(pSEC-LEISS-Afp1) strain (Figure 2B). This suggests that Afp1 alone was produced as a precursor and remained totally confined to the cell fraction, as previously demonstrated in secretion experiments carried out with other heterologous proteins secreted by L. lactis in pSEC systems. The production yields of bovine rotavirus nonstructural protein 4 (NSP4) were ten-fold higher when NSP4 was fused with a signal peptide, when compared to cytoplasmic production. However, the NSP4 precursor form (i.e., signal peptide plus NSP4) remained confined to the cell fraction of the induced recombinant cultures and was subjected to proteolysis (26). Similar results were ob-

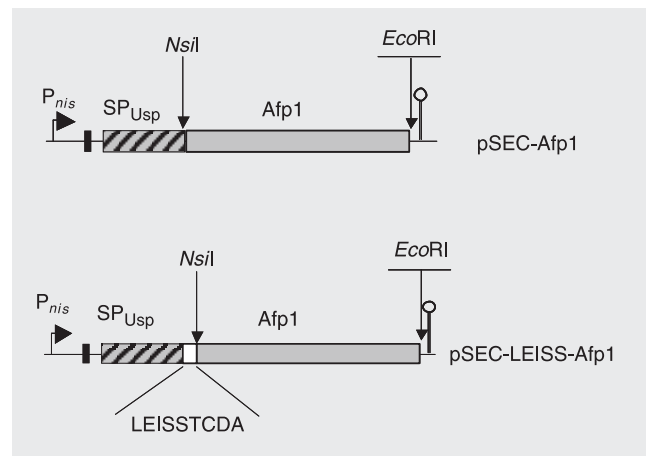

Figure 1. Schematic presentation of antifungal protein 1 (Afp1) cassettes for controlled secretion in Lactococcus lactis. The plasmid backbone is a derivative of the rolling circle plasmid pWV01, an E. coli Gram-positive shuttle vector. Arrows indicate the presence of the nisin-inducible promoter $\left(\mathrm{P}_{\text {nis }}\right)$; solid vertical bars indicate the ribosome binding site of the usp 45 gene; the striped bar indicates the signal peptide of the usp45 gene $\left(\mathrm{SP} \mathrm{Usp}_{\mathrm{sp}}\right)$; the white bar indicates the insertion of the synthetic propeptide LEISSTCDA (19); gray bars indicate the Afp1 coding sequence; stem-loop structures indicate trpA transcription terminators (not to scale). 
tained when bovine B-lactoglobulin (BLG), the dominant allergen in cow's milk, was produced by L. lactis. BLG production was significantly higher when BLG was fused with a lactococcal signal peptide compared with cytoplasmic production. However, BLG secretion was very low, and there was no detectable mature BLG in the supernatant of pSEC-BLG strains (7), whereas BLG was detected in the induced supernatant of a pSEC-LEISS-BLG strain (27). In the case of Afp1, secretion enhancement by fusion with the LEISS propeptide leads to the release of some of the secreted LEISS-Afp1 form in the supernatant, whereas no protein was detected when Afp1 was produced without LEISS.

To our knowledge, LEISS-Afp1 is the smallest non-bacteriocin protein ever pro-
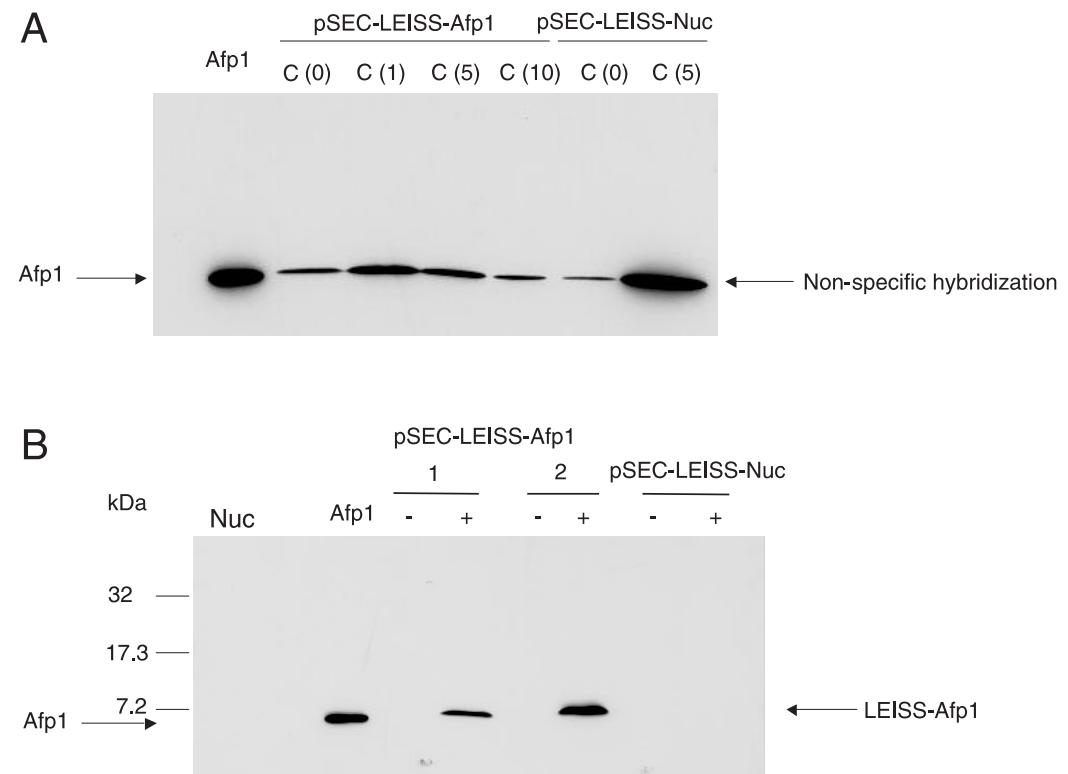

Figure 2. Secretion analysis of Streptomyces tendae antifungal protein 1 (Afp1) in Lactococcus lactis. Afp1 secretion was estimated in exponential phase cultures of recombinant lactococcal strains NZ(pSEC-LEISS-Afp1). The NZ(pSEC-LEISS-Nuc) strain was used as a negative control. Protein samples were prepared from cell and supernatant fractions of non-induced (-) and induced (+) cultures. Induction was performed with $10 \mathrm{ng} /$ $\mathrm{mL}$ nisin over a period of $1 \mathrm{~h}$. $A$, Cell fractions of NZ(pSEC-LEISS-Afp1) and NZ(pSECLEISS-Nuc) cultures induced with increasing amounts of nisin; $C(0)$, cell fraction of noninduced cultures; C (1), C (5), and C (10), cell fractions of cultures induced with 1, 5 and 10 $\mathrm{ng} / \mathrm{mL}$ nisin, respectively. $B$, Supernatant fractions of NZ(pSEC-LEISS-Afp1) and NZ(pSECLEISS-Nuc) cultures not induced (-) or induced (+) with $10 \mathrm{ng} / \mathrm{mL}$ (1 and 2 correspond to two independent experiments). Position and size of molecular weight markers are indicated on the left side. duced through a Sec-dependent pathway in L. lactis. L. lactis is thus able to produce and secrete $<10-\mathrm{kDa}$ proteins through a $\mathrm{Sec}-$ dependent pathway. This bacterium is also able to secrete $>160-\mathrm{kDa}$ proteins (3). Taken together, these facts show that protein size is not a serious bottleneck for heterologous protein secretion in L. lactis.

\section{The secreted LEISS-Afp1 had no detectable antifungal activity}

To check the anti-fungal activity of LEISS-Afp1, supernatants of LEISS-Afp1producing strains were used in growth inhibition agar diffusion assays, using $P$. variotii, A. fumigatus or T. mentagrophytes as test organisms. The growth inhibition test was performed as described in Material and Methods, using untreated culture supernatant or concentrated induced supernatants (up to 100-fold, after freeze-drying). Unfortunately, none of the samples presented any anti-fungal activity (data not shown). This could be due to i) low Afp1 production yields by $L$. lactis strains ( $>4 \mu \mathrm{g} / \mathrm{well}$ was required to observe growth inhibition of $P$. variotii, the fungus most sensitive to inhibition by Afp1 (5)), ii) the absent or improper DSB formation in the LEISS-Afp1 fusion protein (LEISSTCDA introduces a third cysteine residue in the fusion protein), or iii) the addition of several amino acids to the $\mathrm{N}$ terminal moiety of mature Afp1, which interferes with its activity. Although antifungal activities often involve several compounds that may act synergistically (13), Afp1 alone has been found to have an inhibitory effect on $P$. variotii when sufficient amounts are used (5). Thus, a lack of other compound(s) that act synergistically with Afp1 in vivo in $S$. tendae cultures and that may be absent in L. lactis supernatants cannot explain our results. Both the inhibitory spectrum and the inhibitory effect of Afp1 are increased when the chitin synthetase inhibitor nikkomycin, a non-proteinaceous 
compound produced by $S$. tendae, is added to the growth inhibition test (5). Thus, the nikkomycin biosynthesis gene cluster would be a good candidate for future heterologous expression in L. lactis.

From a biotechnological point of view, the lack of antifungal activity of the secreted Afp1 raises questions about protein folding in L. lactis and about the limits in the molecular tools that can successfully enhance heterologous protein secretion, such as introducing a propeptide. They may indeed interfere with the native conformation, thus leading to an inactive chimera. Future studies should investigate the ability of L. lactis to modify heterologous proteins. For example, DSB formation in L. lactis is still poorly understood, and only a few proteins containing DSB have been secreted. BLG is poorly secreted by L. lactis, and the proportion of secreted BLG with a proper conformation has been very low $(7,27)$. On the other hand, other proteins that require DSB, such as murine interleukin-12 (9) and ovine interferon- $\omega$ (8), are efficiently secreted in $L$. lactis. Although L. lactis has the capacity to secrete proteins containing DSB, the genome sequencing of L. lactis did not reveal any lactococcal homologue of $d s b$ or $b d b$, which are the genes involved in DSB formation in E. coli and B. subtilis, respectively. Thus, the production of proteins requiring DSB formation, such as Afp1, is a challenge for the development of L. lactis strains engineered for high-level production of proteins of interest. This type of research could also provide tools for basic research on DSB formation in L. lactis.

\section{References}

1. Nouaille S, Ribeiro LA, Miyoshi A et al. (2003). Heterologous protein production and delivery systems for Lactococcus lactis. Genetics and Molecular Research, 2: 102-111.

2. Le Loir Y, Azevedo V, Oliveira SC et al. (2005). Protein secretion in Lactococcus lactis: an efficient way to increase the overall heterologous protein production. Microbial Cell Factories, 4: 2 .

3. Neubauer H, Bauche A \& Mollet B (2003). Molecular characterization and expression analysis of the dextransucrase DsrD of Leuconostoc mesenteroides Lcc4 in homologous and heterologous Lactococcus lactis cultures. Microbiology, 149: 973-982.

4. Barkocy-Gallagher GA, Cannon JG \& Bassford Jr PJ (1994). Thirtythree amino acids of the mature moiety of an unprocessed maltosebinding protein are sufficient for export in Escherichia coli. Journal of Bacteriology, 176: 3397-3399.

5. Bormann C, Baier D, Horr I et al. (1999). Characterization of a novel, antifungal, chitin-binding protein from Streptomyces tendae Tu901 that interferes with growth polarity. Journal of Bacteriology, 181: 7421-7429.

6. Steidler L, Robinson K, Chamberlain L et al. (1998). Mucosal delivery of murine interleukin-2 (IL-2) and IL-6 by recombinant strains of Lactococcus lactis coexpressing antigen and cytokine. Infection and Immunity, 66: 3183-3189.

7. Chatel JM, Langella $\mathrm{P}$, Adel-Patient $\mathrm{K}$ et al. (2001). Induction of mucosal immune response after intranasal or oral inoculation of mice with Lactococcus lactis producing bovine beta-lactoglobulin. Clinical and Diagnostic Laboratory Immunology, 8: 545-551.

8. Bermudez-Humaran LG, Langella P, Commissaire $\mathrm{J}$ et al. (2003). Controlled intra- or extracellular production of staphylococcal nuclease and ovine omega interferon in Lactococcus lactis. FEMS Microbiology Letters, 224: 307-313.
9. Bermudez-Humaran LG, Langella P, Cortes-Perez NG et al. (2003). Intranasal immunization with recombinant Lactococcus lactis secreting murine interleukin-12 enhances antigen-specific Th1 cytokine production. Infection and Immunity, 71: 1887-1896.

10. Bohra NK \& Purohit DK (2003). Fungal toxicity with special reference to mycotoxins. Journal of Environmental Biology, 24: 213-221.

11. Corsetti A, Gobbetti M, Rossi J et al. (1998). Antimould activity of sourdough lactic acid bacteria: identification of a mixture of organic acids produced by Lactobacillus sanfrancisco CB1. Applied Microbiology and Biotechnology, 50: 253-256.

12. Lavermicocca $P$, Valerio F, Evidente A et al. (2000). Purification and characterization of novel antifungal compounds from the sourdough Lactobacillus plantarum strain 21B. Applied and Environmental Microbiology, 66: 4084-4090.

13. Magnusson J, Strom K, Roos S et al. (2003). Broad and complex antifungal activity among environmental isolates of lactic acid bacteria. FEMS Microbiology Letters, 219: 129-135.

14. Nes IF \& Johnsborg O (2004). Exploration of antimicrobial potential in LAB by genomics. Current Opinion in Biotechnology, 15: 100-104.

15. Magnusson J \& Schnurer J (2001). Lactobacillus coryniformis subsp. coryniformis strain $\mathrm{Si} 3$ produces a broad-spectrum proteinaceous antifungal compound. Applied and Environmental Microbiology, 67: 1-5.

16. Gibson TJ (1984). Studies of the Epstein-Barr virus genome. Doctoral thesis, University of Cambridge, Cambridge, England, UK.

17. Kuipers OP, de Ruyter PG, Kleerebezem M et al. (1997). Controlled overproduction of proteins by lactic acid bacteria. Trends in Biotechnology, 15: 135-140.

18. Birnboim HC \& Doly J (1979). A rapid alkaline extraction procedure for screening recombinant plasmid DNA. Nucleic Acids Research, 
7: 1513-1523.

19. Le Loir Y, Gruss A, Ehrlich SD et al. (1998). A nine-residue synthetic propeptide enhances secretion efficiency of heterologous proteins in Lactococcus lactis. Journal of Bacteriology, 180: 1895-1903.

20. Langella P, Le Loir $Y$, Ehrlich SD et al. (1993). Efficient plasmid mobilization by pIP501 in Lactococcus lactis subsp. lactis. Journal of Bacteriology, 175: 5806-5813.

21. de Ruyter PG, Kuipers OP \& de Vos WM (1996). Controlled gene expression systems for Lactococcus lactis with the food-grade inducer nisin. Applied and Environmental Microbiology, 62: 36623667.

22. Bermudez-Humaran LG, Langella P, Miyoshi A et al. (2002). Production of human papillomavirus type 16 E7 protein in Lactococcus lactis. Applied and Environmental Microbiology, 68: 917-922.

23. Rietsch A \& Beckwith J (1998). The genetics of disulfide bond metabolism. Annual Review of Genetics, 32: 163-184.
24. Le Loir Y, Nouaille S, Commissaire J et al. (2001). Signal peptide and propeptide optimization for heterologous protein secretion in Lactococcus lactis. Applied and Environmental Microbiology, 67: 4119-4127.

25. Eichenbaum Z, Federle MJ, Marra D et al. (1998). Use of the lactococcal nisA promoter to regulate gene expression in grampositive bacteria: comparison of induction level and promoter strength. Applied and Environmental Microbiology, 64: 2763-2769.

26. Enouf V, Langella $P$, Commissaire $J$ et al. (2001). Bovine rotavirus nonstructural protein 4 produced by Lactococcus lactis is antigenic and immunogenic. Applied and Environmental Microbiology, 67: 1423-1428.

27. Nouaille S, Bermudez-Humaran L, Adel-Patient K et al. (2005). Improvement of bovine beta-lactoglobulin production and secretion in Lactococcus lactis. Brazilian Journal of Medical and Biological Research, 38: 343-349. 